\title{
When Tomorrow Comes - Delivering Medicine for the Future
}

\section{Updates in Internal Medicine Symposium organised by the Trainees and Members' Committee}

\author{
Held on 22 October 2010 at the Royal College of Physicians of Edinburgh \\ J Easterbrook \\ Specialist Registrar in Haematology, Western General Hospital, Edinburgh, UK
}

DECLARATION OF INTERESTS No conflict of interests declared.

\author{
Correspondence to J Easterbrook \\ Haematology Department, \\ Western General Hospital, \\ Edinburgh EH4 2XU, UK
}

tel. +44 (0) I3I 5371000

e-mail j.e.pearce@doctors.org.uk
The 40th Collegiate Trainees \& Members' Symposium was an ambitious, forward-looking event that attracted a large and varied audience. Its title reflected its aim to combine informative updates in internal medicine with an insight into the challenges of practising medicine in the future.

The RCPE president, Dr Neil Dewhurst, opened the symposium by reminding us that in an era of ever scarcer resources and increasing public expectation, there will undoubtedly be difficult decisions to be made.

\section{EVERYTHING YOU WISHED YOU KNEW ABOUT...}

Professor John Simpson (Professor of Respiratory Medicine, University of Newcastle) opened the session with an entertaining presentation on community- and hospital-acquired pneumonia. He highlighted our poor antibiotic stewardship and significant overuse of antibiotics in the treatment of pneumonia. He also wisely reminded us that, although we should use the CURB-65 score (confusion of new onset, urea $>7 \mathrm{mmol} / \mathrm{l}$, respiratory rate $\geq 30$ breaths per minute, blood pressure $<90 \mathrm{mmHg}$ systolic or $\leq 60 \mathrm{mmHg}$ diastolic, age $\geq 65$ or older) for assessing the severity of community-acquired pneumonia, it should never be a substitute for clinical acumen.

Professor Alasdair MacLullich (Professor of Geriatric Medicine, Royal Infirmary of Edinburgh) gave a thoughtprovoking talk on delirium, a common and serious problem which is often underdetected and undertreated. He encouraged us to always 'think of delirium' as advocated by recent National Institute for Health and Clinical Excellence (NICE) guidelines.' Given that an episode of delirium is a marker for current and future dementia, he advised us to perform cognitive screening as part of routine follow-up.

Professor Clifford Leen (Honorary Professor and Consultant in Infectious Diseases, Western General Hospital, Edinburgh) used a case study to give us an insight into human immunodeficiency virus (HIV) management in the twenty-first century. If diagnosed and treated early, life expectancy is now very good. He described the likelihood that thresholds for commencing treatment will change in the future and, using the example of the 'Berlin patient', ${ }^{2}$ allowed us to see that there is potential for a cure for HIV in the future.

\section{LOOKING TO THE FUTURE}

In his talk entitled 'Telemedicine - embracing technology to improve healthcare', Professor Gordon Peterkin (Retired Former Director of the Scottish Centre for Telehealth, Aberdeen) delivered a conceptual presentation, encouraging us to be innovative clinicians and drive forward change. Using maritime analogies, he explored the key pillars of successful innovation and the potential barriers to change.

Dr Jim Wilson (Royal Society University Research Fellow, Centre for Public Health Sciences, University of Edinburgh) gave a very different insight into the future. He delivered a dynamic presentation on personalised genomics, exploring the commercial availability of genomic sequencing and providing a glimpse of its potential role in the future while at the same time exposing some of its limitations.

\section{CROOM LECTURE}

DrWilliam Whiteley (Medical Research Council Clinician Scientist, Western General Hospital, Edinburgh) gave the 37th Croom Lecture. This was a fascinating synopsis of his research into the identification of blood biomarkers to improve the diagnosis of stroke $\mathrm{e}^{3,4}$ and he reminded us again that there is rarely a substitute for a thorough clinical history and examination. A review of his research follows on page 152.

\section{DEBATE: HARD TIMES IN THE NHS - WHAT SHOULD WE SPEND THE MONEY ON?}

This was a timely debate with each speaker presenting their view on how we should manage and prioritise the National Health Service budget in the future. 
Dr Jennifer Armstrong (Senior Medical Officer, Scottish Government) argued for disinvestment in interventions with no proven efficacy, while Professor John Frank (Medical Research Council, Scottish Collaboration for Public Health Research) promoted the redistribution of resources, in particular into early childhood development. Dr Christopher Deighton (Clinical Advisor, NICE rheumatoid arthritis guidelines) argued that savings would be made if we treat diseases such as rheumatoid arthritis early and effectively, according to evidence-based guidelines. Dr Miles Witham (Physician and Senior Lecturer, Section of Ageing and Health, Ninewells Hospital and Medical School, Dundee) advocated simple strategies: Stop doing things that do not work, do the things that work well and fix the weak links in the system.

\section{CLINICAL LESSONS}

In the final session six e-Associates and Collegiate Members presented cases, each with important clinical lessons. The e-Associate winner, $\mathrm{Dr}$ Constantinos Parisinos (Foundation Doctor, Western General Hospital), set the standard high with his lively account of a patient with a rare extra-adrenal phaeochromocytoma who had a near-miss with a potentially fatal biopsy. The winning Collegiate Member was Dr Jennifer McCaughan (Specialist Trainee in Renal Medicine, Belfast City Hospital, Belfast). Her elegant description of a case of relapsed systemic lupus erythematosus acknowledged the wisdom of using time as a much underrated and inexpensive diagnostic tool.

\section{TAKE HOME MESSAGES}

'When Tomorrow Comes - Delivering Medicine for the Future' was a thought-provoking symposium, challenging us to face the realities of tomorrow's medicine. Yet its overarching message was to inspire its attendees to be innovative, to have the passion to drive change and the courage to disinvest and redistribute our scarce resources effectively. And, as we learned about an array of ever more complex medical and scientific investigations, we were humbly reminded of the fundamental importance of good clinical skills in the workplace.

\section{REFERENCES}

I National Institute for Health and Clinical Excellence. Delirium: diagnosis, prevention and management. London: NICE; 20I0. Available from: http://guidance.nice.org.uk/CG I03/NICEGuidance/pdf/English

2 Hütter G, Nowak D, Mossner M et al. Long-term control of HIV by CCR5 Delta32/Delta32 stem-cell transplantation. N Engl J Med 2009; 360:692-8. doi:10.1056/NEJMoa0802905

3 Whiteley W, Chong WL, Sengupta A et al. Blood markers for the prognosis of ischemic stroke: a systematic review. Stroke 2009; 40:e380-9. doi: I 0. I I 6 I/STROKEAHA. I08.528752

4 Whiteley W, Lowe GD, Rumley N et al. PAWI8 Blood markers and the diagnosis of stroke or transient ischaemic attack in the emergency department: a prospective cohort study.J Neurol Neurosurg Psychiatry 2010; 8I:e28-9. doi:I0.I I36/jnnp.2010.226340.47

\section{CONTINUING MEDICAL EDUCATION (CME)}

\section{Online distance learning and self-assessment from the RCPE}

To allow users to update their general medical knowledge, the online CME modules contain a variety of material, including articles, interactive cases and quizzes, webstreamed lectures and self-assessment multiple choice questions (MCQs). Each module also includes material of particular relevance to those undertaking core medical training.
CME modules are eligible for external distancelearning Continuing Professional Development (CPD) credits under the UK Federation of Royal Colleges of Physicians CPD scheme. To claim these credits you must take the MCQ test for the module (only available online). Full instructions are given with each module.
The College's online CME programme is available to Fellows, Collegiate Members, Associates and e-Associates. Log on to the Fellows' and Members' secure area at: http://www.rcpe.ac.uk. If you have forgotten your username or password please contact: webmaster@rcpe.ac.uk
Currently available for CPD points

- Rheumatology

- Neurology

- Oncology

Coming soon

- Tropical Medicine

- Respiratory

- Public Health 